\title{
CALIPSO observations of stratospheric aerosols: a preliminary assessment
}

\author{
L. W. Thomason ${ }^{1}$, M. C. Pitts ${ }^{1}$, and D. M. Winker ${ }^{1}$ \\ ${ }^{1}$ NASA Langley Research Center, Hampton, VA, USA \\ Received: 29 March 2007 - Published in Atmos. Chem. Phys. Discuss.: 26 April 2007 \\ Revised: 1 August 2007 - Accepted: 27 September 2007 - Published: 15 October 2007
}

\begin{abstract}
We have examined the 532-nm aerosol backscatter coefficient measurements by the Cloud-Aerosol Lidar and Infrared Pathfinder Satellite Observations (CALIPSO) for their use in the monitoring of stratospheric aerosol. CALIPSO makes observations that span from $82^{\circ} \mathrm{S}$ to $82^{\circ} \mathrm{N}$ each day and, for each profile, backscatter coefficient values reported up to $\sim 40 \mathrm{~km}$. The possibility of using CALIPSO for stratospheric aerosol monitoring is demonstrated by the clear observation of the 20 May 2006 eruption of Montserrat in the earliest CALIPSO data in early June as well as by observations showing the 7 October 2006 eruption of Tavurvur (Rabaul). However, the very low aerosol loading within the stratosphere makes routine observations of the stratospheric aerosol far more difficult than relatively dense volcanic plumes. Nonetheless, we found that averaging a complete days worth of nighttime-only data into 5-deg latitude by $1-\mathrm{km}$ vertical bins yields a stratospheric aerosol distribution that is fairly consistent with past measurements by spaceborne instruments. Based on comparisons with 2004 data from the Stratospheric Aerosol and Gas Experiment, the derived values are close to expectation except in the tropics where they are larger by about a factor of 2 . The cause of the difference in the tropics is not readily apparent but is most likely related to difficulties in the lidar calibration process currently found in the CALIOP data at tropical latitudes.
\end{abstract}

\section{Introduction}

Aerosol plays a significant role in the chemistry and dynamics of the lower stratosphere and upper troposphere including a critical role in the heterogeneous processes that lead to ozone destruction. Stratospheric aerosol is also highly variable due to episodic volcanic eruptions that inject aerosol

Correspondence to: $\mathrm{L} . \mathrm{W}$. Thomason

(1.w.thomason@nasa.gov) and/or its gaseous precursors into the stratosphere. Over the last 25 years, the total aerosol loading has varied by more than a factor of one hundred and volcanic effects have dominated other natural and human-derived sources for stratospheric aerosol in all but the last few years when levels have apparently reached a stable background level (Thomason and Peter, 2006). In the absence of another volcanic eruption, aerosol levels may still undergo significant changes over the next decade due to changes in the human-derived aerosol precursors. Global human-derived $\mathrm{SO}_{2}$ has declined by nearly 20\% since 1980 (Stern, 2003). On the other hand, emissions in East Asia and China have increased dramatically over this period and are projected to continue to increase. It is believed that $\mathrm{SO}_{2}$ or $\mathrm{SO}_{2}$-derived aerosol can reach the upper troposphere/lower stratosphere (UTLS) through entrainment by deep convection in the tropics and, since $\mathrm{SO}_{2}$ has a short lifetime in the troposphere, emissions at low latitudes are far more likely to attain the tropical tropopause than midlatitude emissions (Notholt et al., 2006). As a result, it is possible that changes in human-derived $\mathrm{SO}_{2}$ concentration in the lower stratosphere may produce either an increase or decrease in aerosol loading in the lower tropical stratosphere in the coming years. Changes in aerosol in the UTLS may affect the occurrence and properties of thin cirrus in this radiatively sensitive region (e.g., Kärcher, 2002).

As a result, measurements of stratospheric aerosol remain important, yet global measurements by space-borne instruments are at risk due to the end of the missions of several long-lived instruments (e.g., the Stratospheric Aerosol and Gas Experiment (SAGE II/III), The Halogen Occultation Experiment (HALOE), and the Polar Ozone and Aerosol Measurement (POAM III)) and instrument performance issues for on-going missions (the High Resolution Dynamics Limb Sounder or HIRDLS). Several instruments have the potential to produce stratospheric aerosol data products but have yet to produce them operationally (e.g., SCIAMACHY, ACE-FTS, and MAESTRO). In light of this, we examine the

Published by Copernicus Publications on behalf of the European Geosciences Union. 

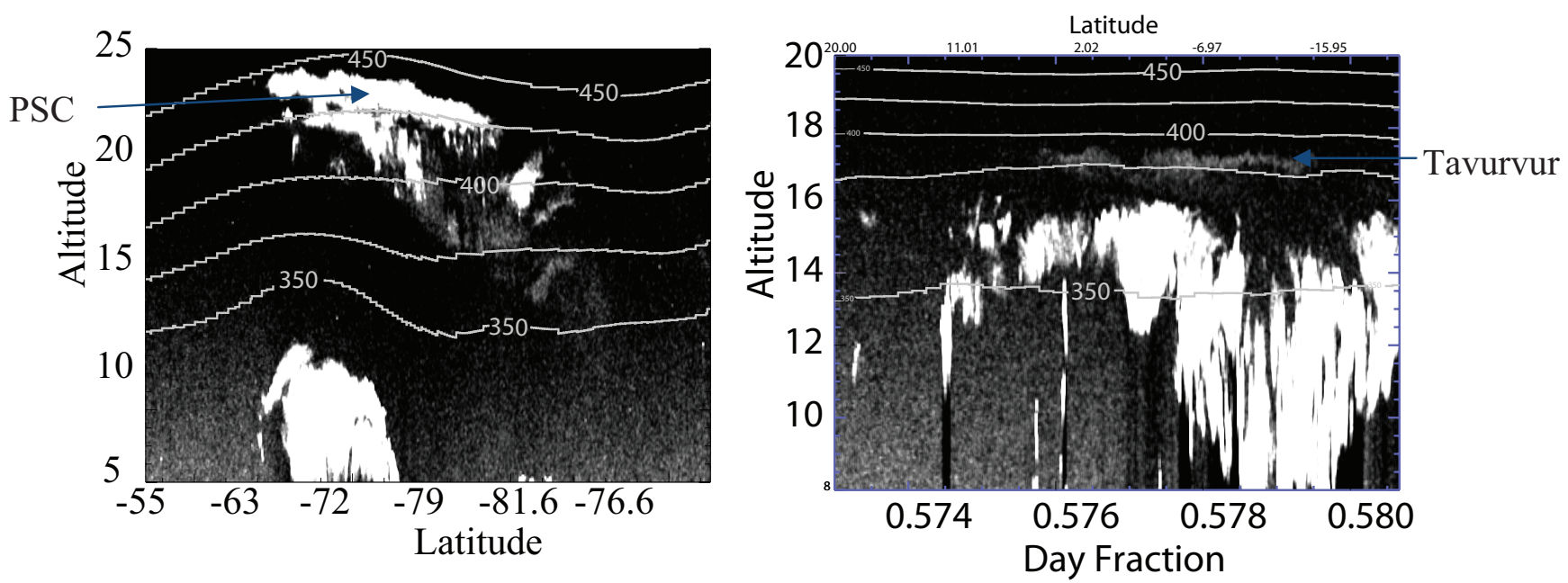

Fig. 1. CALIOP observations of (a) a PSC observed on 24 July 2006 and (b) a qualitative depiction of the volcanic plume from the 7 October 2006 Tavurvur eruption as measured on 15 October 2007. In both frames, the solid grey lines denote potential temperature.

Table 1. CALIOP instrument characteristics.

\begin{tabular}{ll}
\hline laser: & $\begin{array}{l}\text { Nd: YAG, diode-pumped, } \\
\text { Q-switched, frequency doubled }\end{array}$ \\
\hline wavelengths: & $532 \mathrm{~nm}, 1064 \mathrm{~nm}$ \\
pulse energy: & $110 \mathrm{~mJ}$ oule/channel \\
repetition rate: & $20.25 \mathrm{~Hz}$ \\
receiver telescope: & $1.0 \mathrm{~m} \mathrm{diameter}$ \\
polarization: & $532 \mathrm{~nm}$ \\
footprint/FOV: & $100 \mathrm{~m} / 130 \mu \mathrm{rad}$ \\
vertical resolution: & $30-60 \mathrm{~m}$ \\
horizontal resolution: & $333 \mathrm{~m}$ \\
linear dynamic range: & $22 \mathrm{bits}$ \\
data rate: & $316 \mathrm{kbps}$ \\
\hline
\end{tabular}

Cloud-Aerosol Lidar and Infrared Pathfinder Satellite Observations' (CALIPSO) Cloud-Aerosol Lidar with Orthogonal Polarization (CALIOP) lidar backscatter coefficient profiles at $532 \mathrm{~nm}$ as a potential source of a scientifically useful stratospheric aerosol product. While we concede that this is challenging, our preliminary study (explained in detail below) suggests that a scientifically viable data product is possible even for the very low aerosol loading period currently observed.

\section{CALIPSO stratospheric aerosol measurements}

\subsection{Description of CALIPSO}

The primary objective of CALIPSO is to provide measurements that will significantly improve our understanding of the effects of aerosols and clouds on the climate system
Table 2. CALIOP spatial resolution of downlinked data.

\begin{tabular}{lll}
\hline $\begin{array}{l}\text { Altitude } \\
\text { Range }(\mathrm{km})\end{array}$ & $\begin{array}{l}\text { Horizontal } \\
\text { Resolution }(\mathrm{km})\end{array}$ & $\begin{array}{l}\text { Vertical } \\
\text { Resolution }(\mathrm{m})\end{array}$ \\
\hline $30.1-40.0$ & 5.0 & 300 \\
$20.2-30.1$ & 1.67 & 180 \\
$8.2-20.2$ & 1. & 60 \\
$-0.5-8.2$ & 0.33 & 30 \\
$-2.0--0.5$ & 0.33 & 300 \\
\hline
\end{tabular}

(Winker et al., 2007). As part of the Aqua satellite constellation that includes the Aqua, CloudSat, Aura, and PARASOL satellites, CALIPSO is in a $98^{\circ}$ inclination orbit with an altitude of $705 \mathrm{~km}$ that provides daily global maps of the distribution of aerosol and clouds. The CALIPSO payload consists of three instruments: the Cloud-Aerosol Lidar with Orthogonal Polarization (CALIOP), an Imaging Infrared Radiometer (IIR), and a moderate spatial resolution Wide Field-of-view Camera (WFC). CALIOP provides profiles of backscatter at 532 and $1064 \mathrm{~nm}$, as well as two orthogonal (parallel and perpendicular) polarization components at $532 \mathrm{~nm}$. CALIOP instrument characteristic are shown in Table 1 and the vertical and horizontal resolution of the data products is shown in Table 2. A detailed discussion of CALIOP data products can be found in Vaughan et al. (2004). In the routine processing, the parallel component of the 532-nm backscatter is calibrated to the expected molecular volume backscatter coefficient between 30 and $34 \mathrm{~km}$ altitude where the molecular density is derived from the GEOS-4 atmospheric analyses provided by the Global Modeling and Assimilation Office (Bloom et al., 2005; Lin, 2004). The current calibration algorithm does not account 

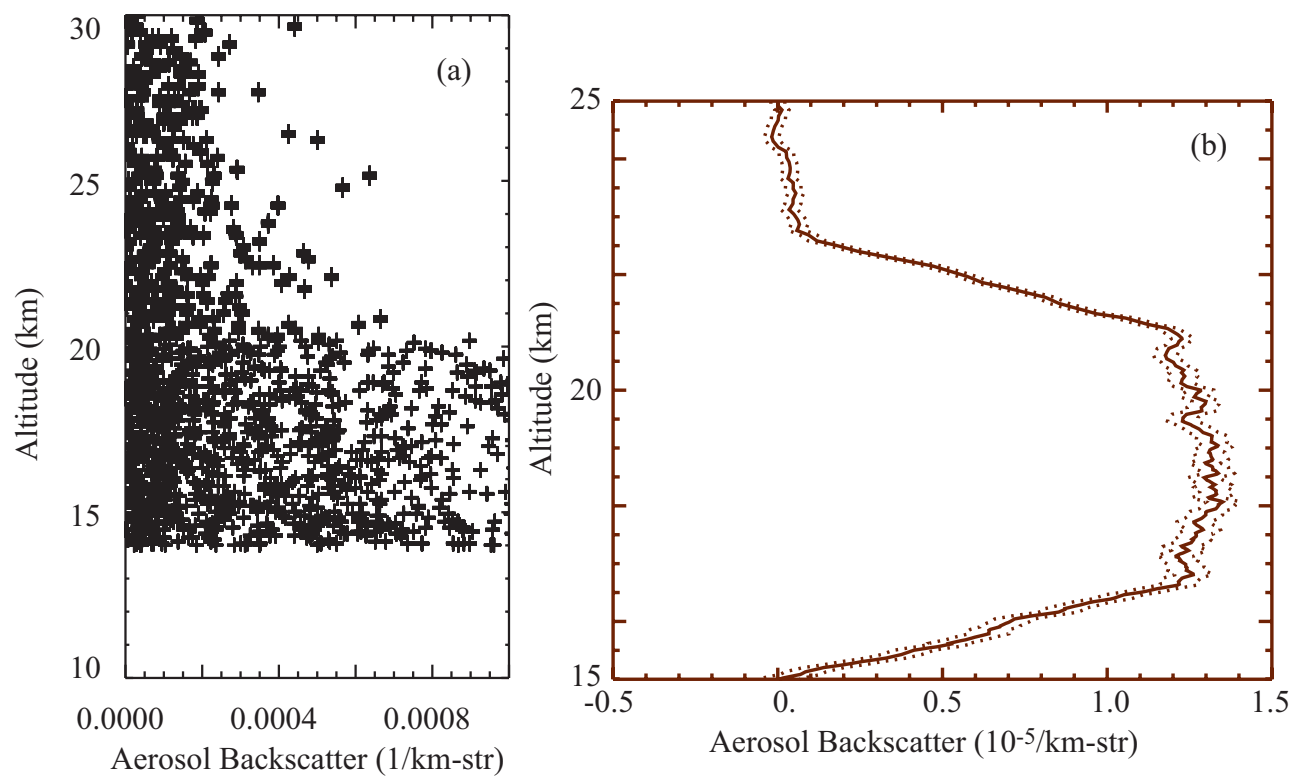

Fig. 2. (a) A depiction of 100 individual simulated CALIPSO 532-nm backscatter profiles for stratospheric layer between 15 and $23 \mathrm{~km}$. The abrupt change in noise at $20 \mathrm{~km}$ is due to a change in on-board smoothing and not due to any atmospheric signal. (b) Simulated retrieval of a stratospheric aerosol layer using CALIPSO backscatter data. This profile is a 1-day, 5-deg latitudinal average for background conditions.

for possible stratospheric aerosol in the $30-34 \mathrm{~km}$ region, as there are currently no available independent global measurements. Independent calibrations occur every $55 \mathrm{~km}$ of the dark side of each orbit and are smoothed using a 27-point mean $(1485 \mathrm{~km})$ (Hostetler et al., 2006) and interpolated onto the sunlit side. The perpendicular component is transferred from the parallel term using an on-board optical system. The calculation of a stratospheric aerosol product is highly sensitive to the quality of this normalization and any deficiency in the calibration represents the greatest obstacle to the successful production of a scientifically useable stratospheric aerosol product.

\subsection{Initial assessment}

With its first observations in mid-June 2006, CALIPSO provided detail of condensed material within the stratosphere. These observations included polar stratospheric clouds (Pitts et al., 2007) as shown in Fig. 1a and a distinct aerosol plume associated with the 20 May 2006 eruption of Montserrat (e.g., Carn et al., 2007). Figure 1b is an example of the observations of a second volcanic event that appeared in the lower tropical stratosphere following the 7 October 2006 eruption of Tavurvur. This plume remained clearly observable in the tropics to at least the end of November 2006. However, apart from these kinds of events, CALIOP backscatter data does not readily show the presence of the stratospheric aerosol layer that has been regularly measured in the past by instruments such as SAGE II and HALOE (see, for example, the browse images at http://www-calipso.larc.nasa.gov/ products/lidar/index.php).
Currently, the mid-latitude stratospheric aerosol column total backscatter (often referred to as integrated backscatter) lies between 2 and $7 \times 10^{-5} \mathrm{str}^{-1}$ at $532 \mathrm{~nm}$ and most of this aerosol lies within 5 to $6 \mathrm{~km}$ of the tropopause (Vaughan and Wareing, 2004). In the main aerosol layer, the total backscatter to molecular-only backscatter ratio (often called the backscatter ratio) is between 1.03 and 1.06. The backscatter ratio can increase above the main aerosol layer due in part to the rapid decrease in molecular backscatter with altitude. The integrated column back scatter is about a factor of 100 less than that following the 1991 Pinatubo eruption and also much less than what can be observed in the boundary layer. With such low values, it is not surprising that stratospheric aerosol was not a science target of the CALIPSO mission. To test the feasibility of producing a stratospheric 532-nm aerosol backscatter product from CALIPSO, we began by making use of the CALIOP data simulator developed by the CALIPSO data processing team (Powell et al., 2002). This simulator includes all known sources of measurement error including shot noise and electronic performance. As input we used a column total of $7.2 \times 10^{-5} \mathrm{str}^{-1}$ at $532 \mathrm{~nm}$ that corresponds to the upper end of ground-based lidar measurements and, based on a $1020 \mathrm{~nm}$ extinction coefficient to 532-nm backscatter coefficient ratio of $20 \mathrm{str}$, is roughly consistent with the stratospheric aerosol optical depth at $1020 \mathrm{~nm}$ reported by SAGE II $(\sim 0.0015)$. Our backscatter profile is a constant $1.2 \times 10^{-5} \mathrm{~km}^{-1} \mathrm{str}^{-1}$ between 17 and $21 \mathrm{~km}$ and linearly decreases to zero by 15 and $23 \mathrm{~km}$. We then produced a $20000-\mathrm{km}$ track using the CALIPSO lidar data simulator. The output was produced at 

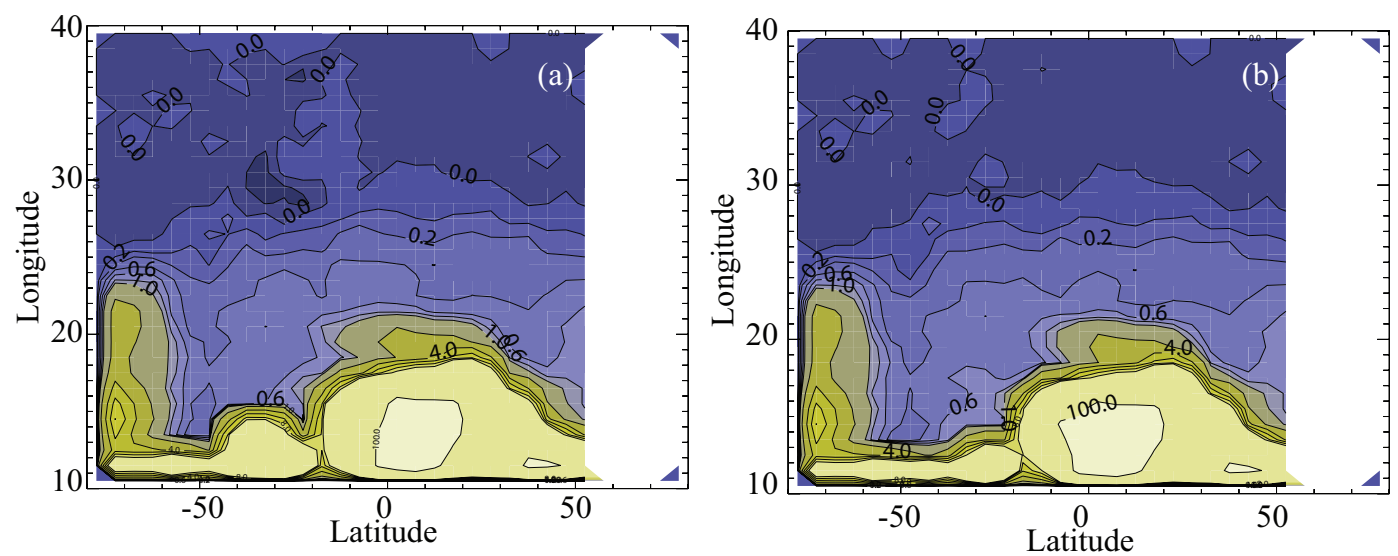

Fig. 3. CALIPSO stratospheric 532-nm aerosol backscatter profiles for (a) 2 July 2006 including all latitudes and longitudes and (b) the same day with all observations between $0^{\circ}$ and $60^{\circ} \mathrm{S}$ and $30^{\circ} \mathrm{E}$ and $90^{\circ} \mathrm{W}$. The contour values are $-0.1,0,0.1,0.2,0.4,0.6,0.8,1,2,4,6$, 8,10 , and 100 for aerosol backscatter coefficient in $\mathrm{km}^{-1} \mathrm{str}^{-1}$ times $10^{5}$. Areas in the troposphere with extinction coefficient values greater than $10^{-4} \mathrm{~km}^{-1} \mathrm{str}^{-1}$ (contour label "10") are strongly influenced by the presence of cloud. Areas within the Antarctic winter time polar vortex show enhanced backscatter due to the presence of polar stratospheric clouds.

the nominal resolution reported by CALIPSO of $1 \mathrm{~km}$ along track and $60 \mathrm{~m}$ vertical resolution below $20 \mathrm{~km}$ and $5 / 3 \mathrm{~km}$ along track and $180 \mathrm{~m}$ vertical resolution above $20 \mathrm{~km}$. We simulated only nighttime measurements in light of the low backscatter levels and noting that nighttime measurements have a much higher signal-to-noise ratio than daytime measurements.

Figure 2a shows 100 individual profiles of this data between 14 and $30 \mathrm{~km}$. Other than the change in resolution (see Table 2) at $20 \mathrm{~km}$, there are no obvious features in this figure and the aerosol layer is invisible. The abrupt change in noise at $20 \mathrm{~km}$ is due to the change in on-board smoothing and not due to any atmospheric signal. Fortunately, there is no overriding reason to produce stratospheric aerosol data at anywhere close to this resolution. The most prominent existing stratospheric aerosol measurement data sets, SAGE II and HALOE, are made by solar occultation and provide a total of only 30 profiles a day and have a horizontal extent of hundreds of kilometers (Thomason et al., 2003). As a result, we feel that substantial averaging to produce a stratospheric product is justifiable and initial assessments of data quality support this conclusion (Winker, et al., 2007). At the same time, given the lack of operational global stratospheric aerosol measurements, even coarser averaging than that representative of current analyses could be justified as a mechanism to preserve stratospheric record. Figure $2 b$ shows the result of reducing the resolution to $1.5 \mathrm{~km}$ vertically and averaging along 15 tracks through a 5-deg latitude band (a total ground track of $7500 \mathrm{~km}$ ) or essentially, a 1-day zonal average. At this resolution, the aerosol layer is clearly visible and the uncertainty in the mean profile is only about $1 \%$. While the simulator is as realistic as possible, it no doubt is missing some components of the measurement noise that are observed in the real data. As a result, we recognize that it is necessary to explore various techniques to produce robust stratospheric aerosol profiles including along track averaging, vertical averaging, and zonal averaging.

\subsection{Application to CALIPSO measurements}

As the initial stratospheric aerosol grid, we chose daily meridianal analyses of all 14/15 nighttime orbit segments averaged in 5-degree latitude bins between $80^{\circ} \mathrm{S}$ and $80^{\circ} \mathrm{N}$ and $1 \mathrm{~km}$ altitude bins covering from 10 to $40 \mathrm{~km}$. This resolution is much less fine than that reported in the standard data product files and spans several changes in horizontal and vertical resolutions in these files (see Table 2). The total number of profiles going into the analysis is on the order of $8 \times 10^{5}$ though replication of data points to account for changes in resolution reduces the effective number of independent measurements. Nonetheless, the volume of data is significantly greater than has been previously available. For instance, the daily number of profiles is almost twice as many profiles as SAGE II produced during its 21-year lifetime. For the initial assessment, we have not made an effort to eliminate cirrus clouds or PSCs. In the future, we will use more sophisticated methods including the use of additional CALIPSO observations such as the 532-nm perpendicular backscatter coefficient and 1064-nm total backscatter coefficient measurements to more effectively deal with the presence of all clouds (e.g., Pitts et al., 2007). The Level 1 backscatter data product (v1.10) is attenuated backscatter which we correct for molecular backscatter and the attenuation by molecules and ozone for the two way trip between the measurement altitude and the spacecraft. We do not currently correct for aerosol attenuation but is very small in the stratosphere at current loadings where the backscatter values are exceedingly small. As a result, while the backscatter values we 


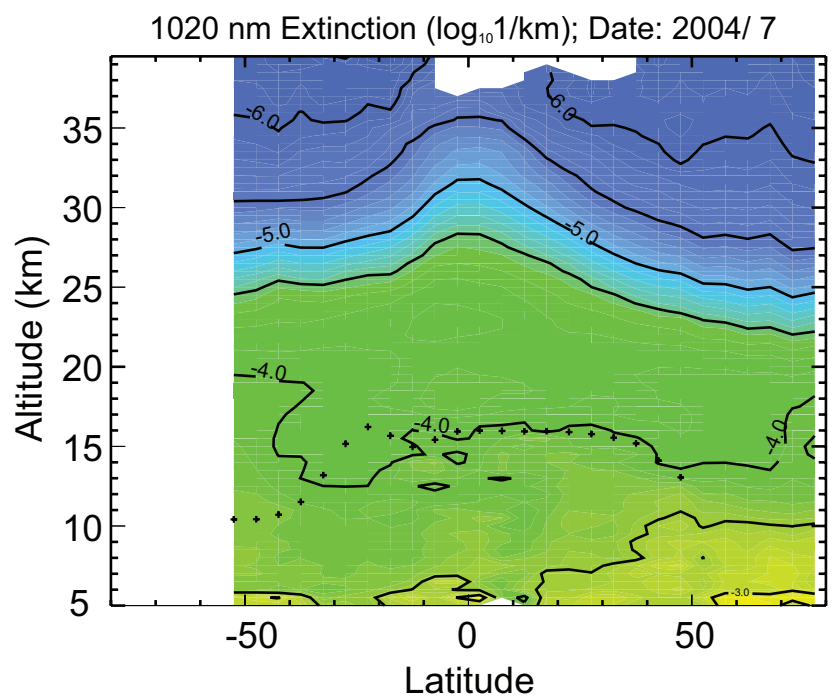

Fig. 4. Cross section of 1020-nm aerosol extinction for July 2004 as measured by the solar occultation instrument SAGE II (in $\mathrm{km}^{-1}$ in $\log _{10}$ ). The "+" signs denote the mean tropopause height. This analysis uses the method developed by Kent et al. (1993) to remove the effect of clouds.

report will underestimate true values, we believe that the use of aerosol attenuated backscatter is unlikely to have a significant effect on the analysis.

Figure 3a shows the aerosol backscatter coefficient meridianal cross section for 2 July 2006. At first glance, the distribution is fairly reasonable. Generally, it decreases above the tropopause except at high southern latitudes where polar stratospheric clouds are frequently observed (Pitts et al., 2007). Since we are not clearing clouds, it is not surprising that the backscatter coefficient increases rapidly below the tropopause particularly in the tropics. There is also a tendency for stratospheric data in the southern hemisphere to show substantial pathologic noise that is associated with the South Atlantic Anomaly (SAA). The SAA is a region where the Van Allen radiation belt dips closest to the Earth's surface and, in this case, exposes CALIOP to increased radiation levels and resultant instrument noise that have made handling this stratospheric data difficult at this juncture. Figure $3 \mathrm{~b}$ shows the same day in which we have eliminated all data between $0^{\circ}$ and $60^{\circ} \mathrm{S}$ and $30^{\circ} \mathrm{E}$ and $90^{\circ} \mathrm{W}$. We have found this to be an effective filter for this analysis and apply it the rest of our analyses.

For comparison purposes, we offer a mean meridianal SAGE II aerosol extinction analysis from July 2004 as shown in Fig. 4. This is a fair comparison because SAGE II is a well-known and well-validated stratospheric aerosol data set and stratospheric aerosol has been relatively constant since 2000 (e.g., Deshler et al., 2006) apart from minor effects by volcanic eruptions such as those by Montserrat and Tavurvur. Figure $3 \mathrm{~b}$ shows substantial regions that are at least reminis-

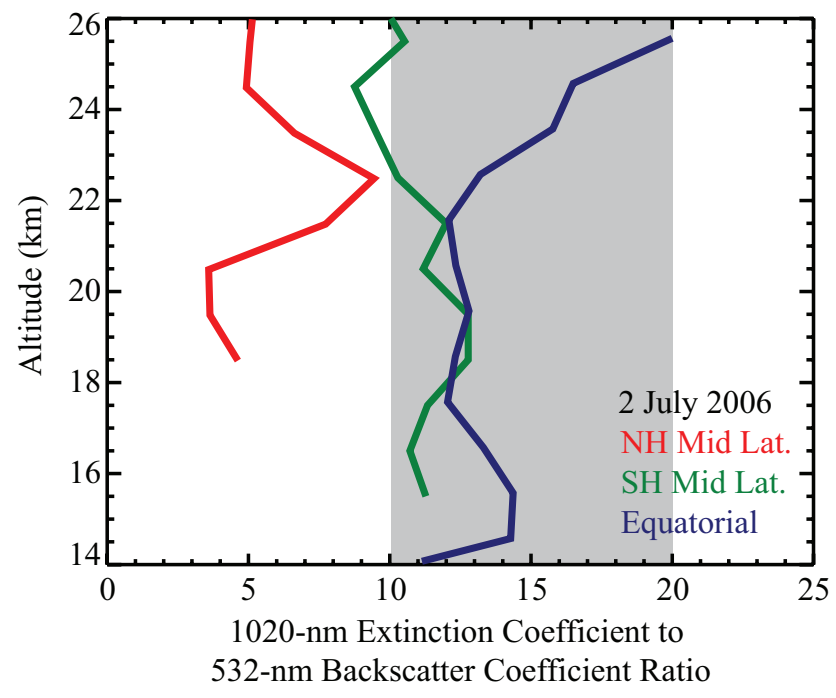

Fig. 5. (a) The ratio of 1020-nm aerosol extinction to 532-nm aerosol backscatter (solid) and the ratio of 1020-nm aerosol extinction to 1064-nm aerosol backscatter as a function of radius for spherical sulfate aerosol at stratospheric temperatures. (b) Ratio of SAGE II 1020-nm aerosol extinction to the 532-nm CALIOP aerosol backscatter coefficient in northern mid-latitudes (green), equatorial (red), southern mid-latitudes (blue) for 2 July 2004. The shaded grey area roughly covers the expected range of the ratio values.

cent of the aerosol layer shown in Fig. 4. Based on a 532-nm extinction to backscatter coefficient ratio of approximately 50 (Jäger and Deshler, 2002, 2003) and a measured SAGE II 525 to $1020-n m$ extinction ratio between 3 and 4 (Thomason et al., 2007), the expected value for the 1020-nm extinction to $532-\mathrm{nm}$ backscatter ratio is between 10 and 20 str. The range roughly corresponds to mean particle size where smaller ratios imply smaller aerosol. This range of values can be inferred from Fig. 5a that shows the ratio of the backscatter and extinction Mie kernels for sulfate aerosol with radii between 0 and $0.5 \mu \mathrm{m}$. There is a potential for smaller values of 1020-nm extinction to 532-nm backscatter coefficient ratio when dominating particle radius is less than $0.1 \mu \mathrm{m}$ possibly occurring in regions of the stratosphere where intense particle formation is occurring.

Figure $5 \mathrm{~b}$ shows the ratio of the SAGE II $1020-\mathrm{nm}$ extinction coefficient (from July 2004) to the CALIOP 532$\mathrm{nm}$ backscatter coefficient at northern and southern midlatitudes $\left(40^{\circ}\right)$ and the equator. The mid-latitude values in both hemispheres are similar and average $\sim 12$ str between 16 and $24 \mathrm{~km}$ with the southern hemisphere ratio slightly smaller than for the northern hemisphere. The value is quite variable above $24 \mathrm{~km}$ where the backscatter coefficient levels decrease rapidly. This value is within the expected range and suggests that the CALIOP data holds some promise for stratospheric applications. On the other hand the ratio at the equator runs between 3 and 7 or something less than half of 


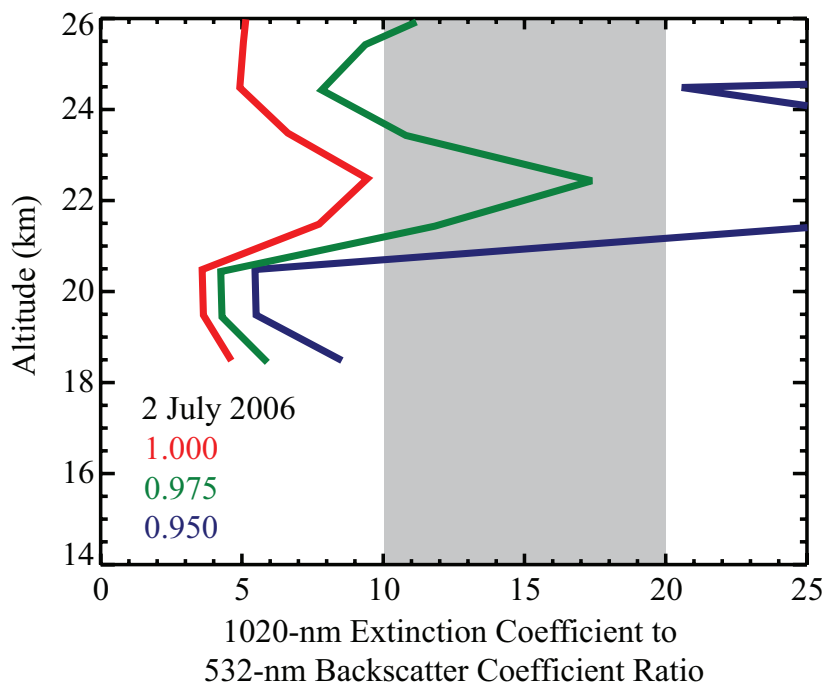

Fig. 6. Ratio of SAGE II 1020-nm aerosol extinction to the 532-nm CALIOP aerosol backscatter at the equator for the standard product (red), adjusted by a factor of 0.975 (green) and by a factor of 0.95 (blue) for 2 July 2004. The shaded grey area roughly covers the expected range of the ratio values.

the expected value. At and below $20 \mathrm{~km}$, the small value is at least partly due to the enhanced backscatter coefficient layer that is the most prominent feature shown in Fig. 5b. This feature is non-depolarizing and therefore not ice or other solid condensed material and is most likely due to the remnant of the Montserrat eruption or other processes discussed below. Above $20 \mathrm{~km}$, the ratio appears to be much too small. It is possible that it is due to variations in the lidar calibration constant that shows a maximum in the tropics. The difficulty in measuring the calibration coefficient in the tropics is due to the need for substantial molecular backscatter with the absence of significant aerosol backscatter. Currently the calibration process assumes a pure molecular atmosphere above $30 \mathrm{~km}$ at all latitudes. On the other hand, Fig. 4 shows that SAGE II measured significant aerosol extinction above 30 $\mathrm{km}$ and that it is approximately 3 times higher in the tropics than at mid and high latitudes. Based on the 2004 SAGE II data, our best estimate is that the backscatter ratio at these altitudes in the tropics is actually at least 1.03 and possibly as large as 1.10 (CALIOP ATDB, 2006). The discrepancy of 3 to $10 \%$ in backscatter ratio translates into a similar magnitude over-estimate of the calibration coefficient for the entire depth of the profile and roughly into an underestimate of the total backscatter coefficient of the same magnitude.

To evaluate the effect of the calibration issue on the stratospheric aerosol backscatter, we performed an experiment by adjusting the equatorial total backscatter profile from Fig. $5 \mathrm{~b}$ by a multiplicative constant, remove the computed molecular backscatter, correct for molecular and ozone attenuation and ratio to the corresponding SAGE II 1020-nm extinction pro- file. Since we need the backscatter to increase, we multiply the total CALIOP 532-nm backscatter coefficient profile by 0.975 and 0.95 and the resulting 1020-nm extinction to 532$\mathrm{nm}$ backscatter coefficient profiles are shown in Fig. 6. Progressively decreasing the total backscatter clearly moves the ratio toward (and through) the range of ratio we expected and suggests that a decrease in total backscatter of a few percent in tropics would improve the data product. Curiously, this change is in the opposite sense that the failure to account for aerosol above $30 \mathrm{~km}$ in the calibration process would push the result. This suggests that either the calibration issue is more complicated than is currently believed or that a geophysical process (e.g., new particle formation) is responsible for moving the extinction-to-backscatter ratio away from expected values. One possible method to produce this error would be a few percent bias in the density data that is used for CALIOP calibration. Further study should help clarify this issue.

\subsection{Some illustrative results}

Figure 7 shows a series of daily cross sections ( 1 day every 4 weeks) of $532 \mathrm{~nm}$ aerosol backscatter coefficient for July 2006 through January. No tropical calibration correction has been included in these images. Here we see very regular behavior in each frame that shows a stratospheric aerosol layer that stretches from about $15 \mathrm{~km}$ to around $22 \mathrm{~km}$. There is a persistent maximum magnitude in the lower tropical stratosphere that generally decreases in magnitude with time. At this point, it is not clear what the primary source of this feature is, however, it is likely that it is related either to the May 2006 Monserrat eruption or a lower tropical aerosol annual cycle that peaks in the second half of the calendar year as has been reported by Thomason et al. (2007). The increase of backscatter coefficient in the lower stratosphere in late 2006 in the southern hemisphere is due to aerosol originating with the October 2006 Tavurvur eruption that appears to have been transported preferentially to southern latitudes in late 2006 in fashion similar to the 1990 eruption of Kelut (Thomason et al., 1997). The presence of PSCs is clearly evident in the southern hemisphere through the 24 September image (Fig. 7d) whereas no clear presence PSCs is noted in the northern hemisphere is observed in December or January (Figs. $7 \mathrm{~g}$ and $7 \mathrm{~h}$ ).

\section{Conclusions}

On the basis of this analysis, we believe that CALIPSO lidar measurements hold some promise for stratospheric applications. The development of a CALIPSO stratospheric aerosol product may provide a bridge between past stratospheric aerosol-measuring instruments like SAGE II and HALOE and future instruments like the Ozone Mapping and Profiler Suite (OMPS). Linking these aerosol data sets is important to 

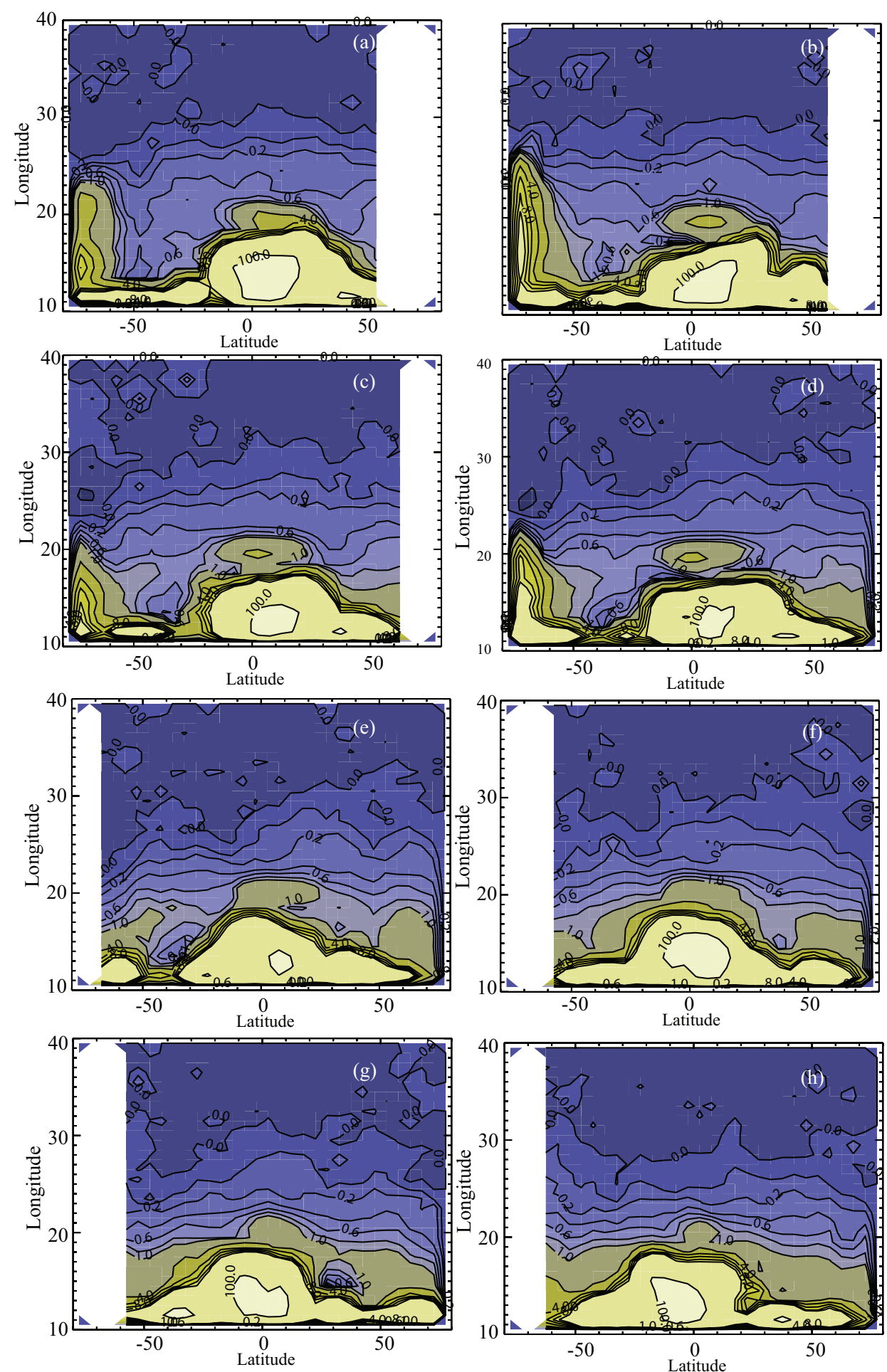

Fig. 7. Cross sections of CALIOP aerosol attenuated backscatter at $532 \mathrm{~nm}$ where the total backscatter has been adjusted for molecular and ozone attenuation and areas impacted by the SAA have been excluded for (a) 2 July 2006, (b) 31 July 2006, (c) 26 August 2006 , (d) 24 September 2006, (e) 22 October 2006, (f) 26 November 2006, (g) 24 December 2006, and (h) 21 January 2007. Red regions have aerosol backscatter less than zero, while white areas showing missing values. The contour values are $-0.1,0,0.1,0.2,0.4,0.6,0.8,1.0,2$., 4 ., 6 ., 8., 10., and 100. for aerosol backscatter coefficient in $\mathrm{km}^{-1} \mathrm{str}^{-1}$ times $10^{5}$. Areas in the troposphere with extinction coefficient values greater than $10^{-4} \mathrm{~km}^{-1} \mathrm{str}^{-1}$ are strongly influenced by the presence of clouds. Areas within the Antarctic winter time polar vortex show enhanced backscatter due to the presence of polar stratospheric clouds. 
maintain trends but far from trivial since none of these instruments measure the same subset of aerosol optical properties and the conversion between measurement types is difficult (e.g., Thomason and Peter, 2006).

It is clear that the examination of the CALIOP stratospheric aerosol data will be useful in evaluating on-going efforts to improve operational data processing. Future releases of the CALIOP calibration process will incorporate aerosol corrections into the calibration process. The quality of the calibration and stratospheric aerosol data are strongly linked and nearly inseparable. As a result, improvements to both are dependent on an assessment of the current quality of the stratospheric data that is dependent either on climatological data, such as the SAGE II data used herein, or on independent corroborative data from ground-based, balloon, or other space-based instruments. Efforts to account for data difficulties associated with the South Atlantic Anomaly by the CALIPSO team are already underway and should allow the use of that data in future analyses.

Acknowledgements. The authors would like to thank M. Vaughan for his helpful comments and K. Powell for performing the CALIOP simulations used in our initial study. We would also like to thank F. Weinhold of ETH Zurich and an anonymous reviewer for their insightful reviews.

Edited by: Q. Fu

\section{References}

Bloom, S., da Silva, A., Bosilovich, M., Dee, D., Chern, J.-D., Pawson, S., Schubert, S., Sienkiewicz, M., Stajner, I., Tan, W.-W., and Wu, M.-L.: Documentation and Validation of the Goddard Earth Observing System (GEOS) Data Assimilation System Version 4, Technical Report Series on Global Modeling and Data Assimilation, NASA/TM-2005-104606, 26, 2005.

Carn, S. A., Krotkov, N. A., Yang, K., Hoff, R. M., Prata, A. J., Krueger, A. J., Loughlin, S. C., and Levelt, P. F.: Extended observations of volcanic SO2 and sulfate aerosol in the stratosphere, Atmos. Chem. Phys. Discuss., 7, 2857-2871, 2007, http://www.atmos-chem-phys-discuss.net/7/2857/2007/.

Deshler, T., Anderson-Sprecher, R., Jager, H., Barnes, J., Hofmann, D. J., Clemesha, B., Simonich, D., Osborn, M., Grainger, R. G., and Godin-Beekmann, S.: Trends in the nonvolcanic component of stratospheric aerosol over the period 1971-2004, J. Geophys. Res., 111, D01201, doi:10.1029/2005JD006089, 2006.

Hostetler, C. A., Liu, Z., Reagan, J., Vaughan, M., Winker, D., Osborn, M., Hunt, W. H., Powell, K. A., and Trepte, C.: CALIOP Algorithm Theoretical Basis Document - Part 1: Calibration and Level 1 Data Products, PC-SCI-201, NASA Langley Research Center, Hampton, VA, (available at http://wwwcalipso.larc.nasa.gov/resources/project_documentation.php), 2006.

Jäger H. and Deshler, T.: Lidar backscatter to extinction, mass and area conversions for stratospheric aerosols based on midlatitude balloonborne size distribution measurements, Geophys. Res. Lett., 29 (19), 1929, doi:10.1029/2002GL015609, 2002.
Jäger H. and Deshler, T.: Correction to "Lidar backscatter to extinction, mass and area conversions for stratospheric aerosols based on midlatitude balloonborne size distribution measurements," Geophys. Res. Lett., 30(7), 1382, doi:10.1029/2003GL017189, 2003.

Kärcher, B.: Properties of subvisible cirrus clouds formed by homogeneous freezing, Atmos. Chem. Phys., 2, 161-170, 2002, http://www.atmos-chem-phys.net/2/161/2002/.

Kent, G. S., Winkler, D. M., Osborn, M. T., and Skeens, K. M.: A model for the separation of cloud and aerosol in SAGE II occultation data, J. Geophys. Res., 98, 20 725-20 735, 1993.

Lin, S. J.: A "Vertically Lagrangian" Finite-Volume Dynamical Core for Global Models, Mon. Wea. Rev., 132, 2293-2307, 2004.

Notholt, J., Luo, B. P., Fueglistaler, S., Weisenstein, D., Rex, M., Lawrence, M. G., Bingemer, H., Wohltmann, I., Corti, T., Warneke, T., von Kuhlmann, R., and Peter, Th.: Influence of tropospheric $\mathrm{SO}_{2}$ emissions on particle formation and the stratospheric humidity, Geophys. Res. Lett., doi:2004GL022159, 2005.

Pitts, M. C., Thomason, L. W., and Poole, L. R.: Characterization of polar stratospheric clouds by the CALIPSO spaceborne lidar: The 2006 Antarctic season, Atmos. Chem. Phys., 7, 1-22, 2007, http://www.atmos-chem-phys.net/7/1/2007/.

Powell, K. A., Hunt, W. H., and Winker, D. M.: Simulations of CALIPSO Lidar Data, in: Lidar Remote Sensing in Atmospheric and Earth Sciences, edited by: L. R. Bissonnette, G. Roy and G. Valle, Defence R\&D Canada -Valcartier, Québec, Canada, pp. 781-784, 2002.

Stern, D. I.: Global sulfur emissions in the 1990s, Rensselaer Working Papers in Economics No. 0311, Rensselaer Polytechnic Institute, Troy, N. Y., U.S.A., 33 pp, 2003.

Thomason, L. W., Herber, A. B., Yamanouchi, T., and Sato, K.: Arctic Study on Tropospheric Aerosol and Radiation: Comparison of tropospheric aerosol extinction profiles measured by airborne photometer and SAGE II, Geophys. Res. Lett., 30, 13281331, doi:10.1029/2002GL016453, 2003.

Thomason, L. W. and Peter, T.: Assessment of Stratospheric Aerosol Properties (ASAP), SPARC Report No. 4, WCRP-124, WMO/TD-No. 1295, http://www.atmosp.physics.ca/SPARC/, February 2006.

Thomason, L. W., Poole, L. R., and Randall, C. E.: SAGE III aerosol extinction validation in the Arctic winter: comparisons with SAGE II and POAM III Atmos. Chem. Phys., 7, 1423-1433, 2007 , http://www.atmos-chem-phys.net/7/1423/2007/.

Thomason, L. W., Burton, S. P., Luo, B.-P., and Peter, T.: SAGE II measurements of stratospheric aerosol properties at non-volcanic levels, Atmos. Chem. Phys. Disc., 7, 6959-6997, 2007.

Vaughan, G. and Wareing, D. P.: Stratospheric aerosol measurements by dual polarization lidar,Atmos. Chem. Phys., 4, 24412447, 2004.

Vaughan, M., Young, S., Winker, D., Powell, K., Omar, A., Liu, Z., Hu, Y., and Hostetler, C.: Fully automated analysis of spacebased lidar data: an overview of the CALIPSO retrieval algorithms and data products, Proc. SPIE, 5575, pp. 16-30, 2004.

Winker, D. M., W. H. Hunt, and M. J. McGill: Initial performance assessment of CALIOP, Geophys. Res. Lett., 34, L19803, doi:10.1029/2007GL030135, 2007. 